\section{Aggressiveness, anxiety and drugs}

SIR: Kirov (Journal, December 1989, 155, 846) equates the control of anxiety and aggression: drugs which control anxiety control aggression, and those which aggravate anxiety aggravate aggression.

Clinically, this is often not true, particularly in the field of child protection from abusive carers. Alcohol or tranquillisers can make the parent/carer more dangerous. The mechanism for this is that the parent already hates, resents, or is frustrated by the dependent child. Theoretically, the aggression itself could be dulled by the anti-anxiety drug (alcohol, benzodiazepine or barbiturate). However, cortical restraint is also damped down, releasing or aggravating whatever aggressive propensities remain.

This throws a caution on Professor Kirov's last paragraph, in which optimism is expressed that antianxiety drugs will control aggression.

\section{Burderop Hospital}

JACK E. OLIVER

\section{Wroughton}

Swindon, Wilts SN4 OQA

\section{Limitations of double-blind trials}

SIR: Newcombe (Journal, February 1990, 156, 282), in his letter on double-blind trials, continues to defend randomised controlled trials in psychiatric research (Newcombe, 1988), without apparently recognising their limitations (Kramer \& Shapiro, 1984). In particular, he does not accept the fallibility of the double-blind and criticises Oxtoby et als (1989) suggestion that the ability of participants to guess their drug status should be used as a retrospective criterion to exclude certain results. Dr Newcombe's caution about this latter suggestion is justified, although the recording of guesses of whether patients were taking active drugs or placebo can be of value. As a recent example, Marks et al (1988) found that assessors' guesses after the end of treatment were mostly right. They did not assess the blindness of patients but suggested that such checks might yield similarly sobering data. Moreover, Oxtoby et al (1989) advocate reworking results when the double-blindness has been disnroven. and the of its efforts is a lot more complicated than Leff supposes. For example, in the Kasongo vaccination project in Zaire (Kasongo Project Team, 1981), while a high coverage of measles immunisations was achieved and led to a noticeable reduction in measles mortality, the overall mortality was not affected. The same number of children perished, but from other causes. Was the medical intervention successful? By what criteria do we judge? know whether the issues that Dr Newcombe raises about upsetting the randomisation and similar problems would be relevant to this study.

Perhaps a more appropriate conclusion to draw from this debate is that clinical trials are unlikely to be definitive in the scientific sense that Dr Newcombe would like. Interpretation of results is inevitably important, which may explain why there is so much controversy about the effectiveness of psychiatric treatment.

Department of Psychiatry

D. B. DOUBLE

University of Sheffield

Northern General Hospital

Sheffield S5 $7 \mathrm{AU}$

\section{References}

Karlowski, T. R., Chalmers, T. C., Frenkel, L. D. et al. (1975) Ascorbic acid for the common cold. Journal of the American Medical Association, 231, 1038-1042.

Kramer, M. S. \& Shaptro, S. H. (1984) Scientific challenges in the application of randomised trials. Journal of the American Medical Association, 252, 2739-2745.

Marks, I. M., Lellott, P., BAsoglu, M., et al. (1988) Clomipramine, self-exposure and therapist-aided exposure for obsessivecompulsive rituals. British Journal of Psychiatry, 152, 522-534.

NEwCOMBE, R. G. (1988) Evaluation of treatment effectiveness in psychiatric research. British Journal of Psychiatry, 152, 696-697. OXTOBY, A., JONEs, A. \& ROBnNsON, M. (1989) Is your 'double-blind' design truly double-blind? British Journal of Psychiatry, 155, 700-701.

\section{Reviewing reviewers}

SIR: I am writing to defend Macdiarmid's review of Ellenberger's The Discovery of the Unconscious (Journal, January 1990, 156, 135-139) against what I consider to be a naive and rather arrogant criticism by Brooks (Journal, May 1990, 156, 747).

I would consider that skimming, followed by selective 'dipping', is an important part of the reviewers art. This may indeed proceed to more thorough reading and re-reading, depending on the nature and merits of the text being considered. Macdiarmid himself clearly appreciated this long book as a reference text and for selective re-reading. In this he was realistic as well as admirably honest.

I take iscue with the cllooestinn that reviewers muet paper which, contrary to Leff's interpretation, neither idealises nor romanticises insanity, but rather demonstrates how intellectual innovation can arise from a particular society's reponse to the inversion of normal behaviour by two messianic leaders who experienced episodes of psychosis.

Dr Littlewood's review includes some suggestions on how clinically applied anthropology can, for example, enhance the role of the liaison psychiatrist 